\title{
Studies of the Functions of Natural Killer-Interferon System in Patients with Sjögren Syndrome
}

\author{
Nagahiro Minato, Akira Takeda, Shogo Kano, and Fumimaro Takaku, \\ Division of Clinical Immunology, Department of Medicine, Jichi Medical \\ School, Tochigi, Japan 32904
}

A B S T R A C T The natural killer (NK)-interferon (IFN) system is shown to be significantly involved in the resistance of host to viral infections and to tumors in numbers of animal models (1-4). The patients with Sjögren syndrome (SS) as well as those with collagen diseases were systematically investigated for the functions of NK-IFN system, including endogenous and augmented NK activity, IFN production, and responsiveness of NK cells to IFN stimulation, using virus persistently infected cells (HeLa-measles cells) as target and stimulator cells. Although endogenous NK activity was not reduced, augmented NK activity by HeLa-measles cells in vitro was significantly depressed in patients with SS compared with that in age-matched normal controls. The patients with SS had also impaired capacity to produce IFN, which is shown to be a major factor regulating $\mathrm{NK}$ activity $(5,6)$ in response to HeLa-measles cells in vitro. In three patients with SS who showed severely depressed NK activity, the effect of exogenous IFN was examined, and virtually no augmentation of NK activity was observed in all cases. Under the same condition, the normal controls deomonstrated a dramatic increase in NK activity. The reduced IFN production was observed in all examined patients with SS, whereas impaired augmentation of NK activity by the stimulation with HeLa-measles cells as well as IFN seemed to be more striking in patients with the systemic manifestations of the disease, such as hypergammaglobulinemia and lymphoid hyperplasia. The possible involvement of dysfunction of NKIFN system in the systemic manifestations of SS is discussed.

\section{INTRODUCTION}

Sjg̈ren syndrome $(\mathrm{SS})^{1}$ is a chronic disease characterized by "sicca" symptoms due to the lymphoid cell

Received for publication 8 June 1981 and in revised form 23 September 1981.

${ }^{1}$ Abbreviations used in this paper: IFN, interferon; MLTC, mixed lymphocyte-tumor cell culture; NK, natural infiltration of exocrine glands (7). The etiological causes in pathogenesis of SS are still unknown. The possibility of involvement of viral infections, for example, has been raised $(8,9)$, but has never been established. In SS, there are frequent systemic manifestations including hypergammaglobulinemia with various kinds of autoantibodies, varying degrees of lymphoproliferation from benign, transient lymph node swellings to overt malignant lymphomas, and the involvement of other organs $(7,10)$. It is also frequently associated with other autoimmune diseases (7). These and other observations, in which a number of conventional immunological responses were reported to be abnormal in patients with SS $(11,12)$, strongly suggest the involvement of immune dysfunctions in the pathogenesis of SS.

In our study, we systematically investigated the functions of natural killer (NK)-interferon (IFN) system in patients with SS. NK cells were originally reported by Herberman et al. (13) and Kiessling et al. (14) as spontaneously cytotoxic cells to various tumor cells, especially of lymphoid origin, in lymphoid organs of nonimmunized animals. We $(15,16)$ and others (17) have found that these NK cells were also preferentially effective in killing virus-infected cells, and that IFN played a central role in the regulation of NK activity, providing the concept of an NK-IFN system as a distinct host defense mechanism against virus infections and tumors. The NK cell is also considered to be one of the candidates for the immune surveillance mechanism of the host against tumors, based on the observations in congenitally athymic nude mice (18, 19). We examined various aspects of the NK-IFN system in patients with SS in comparison with those with collagen diseases as well as in normal controls using virus persistently infected tumor cells, including en-

killer; PBL, peripheral blood lymphocytes; PSS, progressive systemic sclerosis; RA, rheumatoid arthritis; SLE, systemic lupus erythematosus; SS, Sjogren syndrome. 
dogenous and augmented NK activity, IFN production, and the responsiveness of NK activity to IFN.

\section{METHODS}

Patient population. 13 patients with Sjögren syndrome (SS), all female, aged from 30 to $71 \mathrm{yr}$, seen in the Collagen Disease Clinic at Jichi Medical School, Tochigi, Japan, were studied. SS was diagnosed according to the Bloch's criteria (7). The presence of xerostomia was confirmed by salivary flow rate, sialography and scintiscanning of parotid glands, and finally by the histological examination of the labial salivary gland biopsy specimens. Keratoconjunctivitis sicca was diagnosed by the staining with Rose-Bengal and by Schirmer tear test. Of 13 patients, 8 had only glandular diseases, 2 had definite rheumatoid arthritis (RA), 1 had progressive systemic sclerosis (PSS), 1 had chronic active hepatitis, and 1 had chronic thyroiditis (Hashimoto's disease). None of the patients were receiving corticosteroids or other immunosuppressive drugs. Nine patients with systemic lupus erythematosus (SLE), PSS, or RA without SS were also included in this study for comparison. SLE and RA were diagnosed according to the diagnostic criteria of American Rheumatism Association. Five patients with SLE or PSS were all fresh cases and had never been treated with any medications at the time of the investigation, and the patients with RA had been receiving nonsteroidal antiinflammatory drugs including aspirin. The normal controls consisted of 27 individuals: 2 males and 25 females. Because the age distributions of the different disease categories investigated were different, the normal controls were divided into two groups, the younger group (18-39-yr-old) and the older group (40-55-yr-old) for the comparative analysis. As shown in Results, however, no significant difference in the function of NK-IFN system was observed between these two control groups.

Separation of mononuclear cells. Separation of peripheral blood lymphocytes (PBL) was performed by the density gradient centrifugation method. Briefly, heparinized blood was diluted with phosphate-buffered saline, layered on Ficoll-sodium isotalamate (S.G. 1.077), and centrifuged at $400 \mathrm{~g}$ for $30 \mathrm{~min}$ at room temperature. The cells in interphase were collected, washed, and resuspended in RPMI 1640 medium supplemented with $10 \%$ fetal calf serum, 2 $\mathrm{mM}$ L-glutamine, $100 \mathrm{U} / \mathrm{ml}$ penicillin, $100 \mathrm{U} / \mathrm{ml}$ streptomycin, and $10 \mathrm{mM}$ Hepes (complete RPMI 1640 medium).

Target cells. HeLa cells persistently infected with measles virus (HeLa-Ms) were originally obtained from Dr. J. Holland (University of California, San Diego, Calif.). HeLaMs cells were maintained as monolayer culture in Eagle's minimal essential medium supplemented with $8 \%$ calf serum, L-glutamine, penicillin, streptomycin, and Hepes. The characteristics of the virus persistently infected cell lines were described elsewhere (20). Human amnion-derived cell line cells for the interferon assay were cultured in minimal essential medium with $5 \%$ fetal calf serum.

Mixed lymphocyte-tumor cell culture (MLTC). $1 \mathrm{ml}$ of PBL at a concentration of $5 \times 10^{6}$ cells $/ \mathrm{ml}$ in complete RPMI 1640 medium were cultured for $18 \mathrm{~h}$ either alone or with $10^{5} \mathrm{HeLa}-\mathrm{Ms}$ cell monolayers that had been prepared the day before in 24 well Linbro multiculture dishes (Flow Laboratories, Inc., Rockville, Md.). Preliminary experiments indicated that significant NK augmentation occurred as early as $3 \mathrm{~h}$ after the contact with HeLa-Ms cells, reached a plateau within 9-24 h, and declined thereafter. IFN production was shown to reach the peak at $\sim 12 \mathrm{~h}$, keeping the level for 24 to $48 \mathrm{~h}$. Thus, the period of 18 -h incubation of PBL with
HeLa-Ms cells was routinely chosen to examine both NK augmentation and IFN production in MLTC. The nonadherent cells were then harvested, transferred to new dishes, and incubated again for another $5 \mathrm{~h}$ to allow adherent cells to reattach to the dishes. The procedure was routinely performed to prevent the carry-over of HeLa-Ms cells into the succeeding assay system as much as possible. Again, the nonadherent cells, which were now almost free of HeLa-Ms cells, were finally harvested for NK assay. The culture supernates were immediately frozen at $-60^{\circ} \mathrm{C}$ for the assay of IFN activity. The cytotoxic activity of the PBL cultured alone will be referred as "endogenous NK activity". It was equivalent to or even slightly higher than that found in freshly isolated PBL, most likely due to the elimination of adherent cells. The cytotoxic activity of the PBL precultured with HeLa-Ms cells, on the other hand, will be referred as "augmented NK activity". IFN activity in the culture supernates of PBL and HeLa-Ms cells was largely resistant to treatment by $\mathrm{pH} 2.0$ for $24 \mathrm{~h}$ and derived from non-E-rosetting, nonadherent cells. It was therefore classified as IFN $\alpha$.

Cytotoxicity assay. HeLa-Ms cells were trypsinized, and $5 \times 10^{5}$ cells in suspension were incubated with $100 \mu \mathrm{Ci}$ $\mathrm{Na}_{2}{ }^{51} \mathrm{CrO}_{4}$ (RCC Amersham, Amersham Corp., Arlington Heights, Ill.) for $1.5 \mathrm{~h}$ at $37^{\circ} \mathrm{C}$ in $5 \% \mathrm{CO}_{2}$-air incubator. The cells were then washed three times, resuspended, and incubated for another $5 \mathrm{~h}$ with frequent shaking to allow the membrane components essential for the NK cell-mediated lysis to regenerate after the trypsinization. The ${ }^{51} \mathrm{Cr}$-labeled HeLa-Ms cells $\left(10^{4}\right)$ were then mixed with varying numbers of effector cells in 96 well-microculture plate (Falcon, Labware, Div. Becton, Dickinson \& Co., Oxnard, Calif.) and incubated for $6 \mathrm{~h}$. In every point, triplicate cultures were set up. The culture supernates were then harvested with Titertek Supernatant Collection System (Flow Laboratories, Inc.), and the radioactivities were counted by gamma-counter (Aloka ARC-451, Aloka, Co. Ltd., Tokyo, Japan). The percentage of specific ${ }^{51} \mathrm{Cr}$ release was calculated as follows: percentage of specific ${ }^{51} \mathrm{Cr}$-release $=($ experimental release - spontaneous release)/(maximum release - spontaneous release) $\times 100$, where maximum release was determined by the addition of $1 \%$ Triton X-100 solution (Sigma Chemical Co. St. Louis, Mo.). Spontaneous ${ }^{51} \mathrm{Cr}$-release for HeLa-Ms cells was $\sim 10 \%$.

IFN assay. IFN activity in the culture supernates of various MLTC was assayed as described (16) using microcytopathic effect inhibition assay. Human amnion-derived cell line cells (kindly supplied from Dr. T. Kishida, Kyoto Prefectural University, Kyoto, Japan) were used as indicator cells and vesicular stomatitis virus was used as the challenging virus. The inverse figures of the dilutions of the samples to protect $\sim 50 \%$ of human amnion-derived cell line cells from the cytopathic effect by vesicular stomatitis virus infection were used as antiviral (IFN) titers. One unit in our assay was approximately equivalent to one international unit.

Purified IFN and antihuman IFN serum. Human leucocyte IFN induced by Sendai virus and purified by affinity chromatography with monoclonal antihuman IFN antibody (sp act of $10^{7} \mathrm{U} / \mathrm{mg}$ protein) was kindly supplied by Dr. Imai (Jichi Medical School, Japan). Rabbit antihuman IFN $\alpha$ serum (neutralization titer $>10^{3}: 1$ against $10 \mathrm{U}$ of human IFN) was a generous gift from Dr. Kishida (Department of Microbiology, Kyoto Prefectural College of Medicine, Kyoto, Japan).

Statistical analysis. Data were statistically analysed by Student's $t$ test. 


\section{RESULTS}

Endogenous and augmented NK activity in patients with SS. Endogenous and in vitro augmented NK activity by the stimulation with HeLa-Ms was studied in 13 patients with SS in comparison with that in normal controls, patients with collagen diseases without SS, and patients with virus infections. HeLaMs cells were used as target cells. The results are summarized in Fig. 1. The endogenous NK activity in patients with SS was not different from that in normal controls, whereas the augmented NK activity was found to be significantly depressed in patients with SS $(29.9 \pm 16.5)$ as compared with that in age-matched normal controls $(54.9 \pm 14.4)(P<0.01)$. Because some of the patients with SS were associated with RA or PSS, the NK activity of patients with RA or PSS without SS was also examined. Neither endogenous nor augmented NK activity in these patients was depressed. Using K562 as target cells, it was reported that the patients with SLE had reduced NK activity $(21,22)$. As also shown in Fig. 1, no augmentation of NK activity was observed in patients with SLE, although endogenous NK activity seemed to be maintained in these patients against HeLa-Ms cells. In animal experiments it is known that NK activity is augmented rapidly following acute virus infections $(23,24)$. We thus examined NK activity of three patients who had probable virus infection with the evidence of hepatitis by liver biopsy and lymphadenopathy. Endogenous
NK activity in these patients tended to be already markedly elevated and further augmentation by the contact with HeLa-Ms cells was also observed. To ascertain the reproducibility of experiments as well as the observations above, NK activity in normal individuals and in patients with SS or virus infections was repeatedly examined in independent assays after intervals of at least 1 mo. The results are shown in Table I. First, both endogenous and augmented NK activity in each individual of normal controls were quite reproducible in independent assays. Second, the depression of NK activity in several patients with SS was constantly observed by multiple assays over the periods of months to a year, although in some other patients the NK activity was close to normal. A patient (case 1) had received extensive plasmapheresis between these assays without essential changes in NK activity. In another patient (case 5), there was elevated endogenous NK activity in two independent assays, whereas no further augmentation by the co-culture with HeLaMs cells was observed in both experiments. In contrast, marked elevation in endogenous NK activity in patients with virus infections was followed by decline in activity by the second examination after a month or so, when clinical signs and symptoms also subsided.

Depression of the IFN production in patients with SS. The important role of IFN in the regulation of NK activity has been well established in both murine and human systems $(5,6)$. In the murine system, we have shown that the augmentation of NK activity by

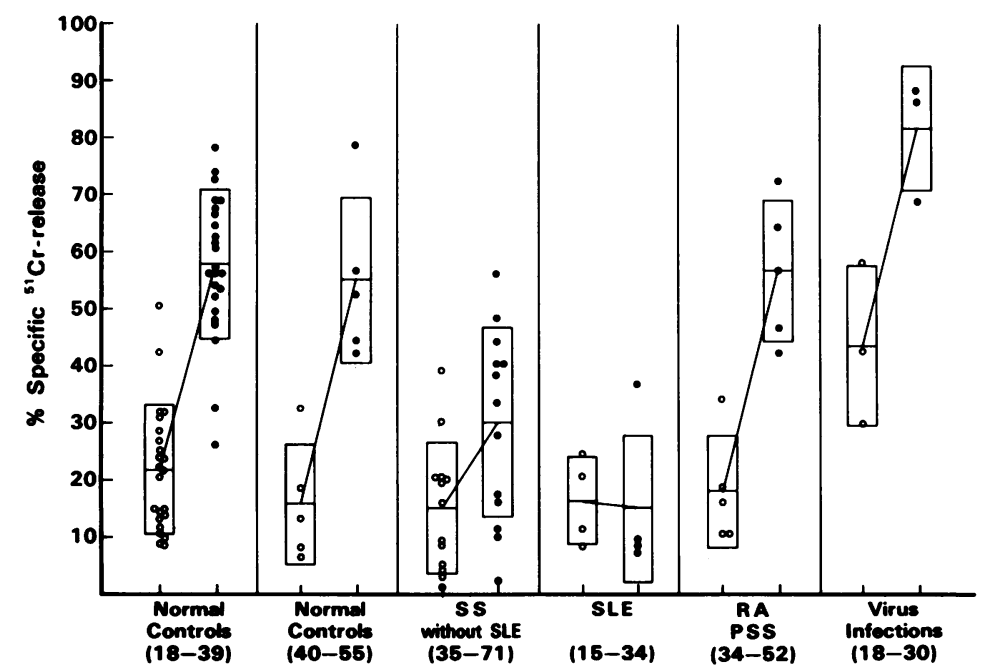

FIGURE 1 Endogenous and in vitro augmented NK activity of PBL from different ages of normal controls, patients with SS, SLE, RA or PSS, and patients with acute viral infections. Freshly isolated PBL were cultured alone $(O)$ or with HeLa-measles cells $(\bullet)$ for $18 \mathrm{~h}$, and nonadherent cells were harvested as described in Methods. The cytotoxic activity of these cells against HeLa-measles cells was assayed using 6-h ${ }^{51} \mathrm{Cr}$-release assay at 50:1 $\mathrm{A} / \mathrm{T}$ ratio. All experiments were set up in triplicate. Each point represents the mean value of one to four independent experiments of each individual. The mean $\pm S D$ in each group is also indicated. 
TABLE I

Repeated Examinations of Endogenous and Augmented NK Activity by HeLa-Measles Cells of Normal Individuals, Patients with SS, and Patients with Acute Viral Infections

\begin{tabular}{ccccc} 
& No. of & & Mean NK activity against HeLa-Ms & \\
\cline { 3 - 5 } $\begin{array}{c}\text { Donors of } \\
\text { PBL }\end{array}$ & $\begin{array}{c}\text { experi- } \\
\text { ments }\end{array}$ & Endogenous & Augmented & Net increase NK \\
\hline
\end{tabular}

$\%$

\begin{tabular}{lllllr} 
Normal & 1 & 2 & $17.0(12.6,21.3)$ & $58.2(63.6,52.8)$ & 41.2 \\
& 2 & 2 & $22.3(20.7,23.9)$ & $67.1(62.1,72.1)$ & 44.8 \\
& 3 & 2 & $10.6(9.5,11.7)$ & $54.8(45.3,66.0)$ & 44.2 \\
& 4 & 2 & $9.4(13.7,5.1)$ & $55.5(55.7,55.2)$ & 46.1 \\
& 5 & 2 & $22.3(20.7,23.9)$ & $67.1(62.1,72.1)$ & 44.8 \\
& 6 & 2 & $13.3(8.9,17.6)$ & $56.6(65.9,47.7)$ & 43.3 \\
\hline \multirow{2}{*}{ jögren } & 1 & 3 & $8.5(12.3,11.9,1.2)$ & $9.9(7.0,20.8,1.8)$ & 1.4 \\
& 2 & 4 & $3.1(1.0,1.5,3.6,6.4)$ & $11.4(1.8,8.7,15.3,19.8)$ & 8.3 \\
& 3. & 2 & $1.4(0.0,2.8)$ & $2.2(0.0,4.4)$ & 0.8 \\
& 4. & 2 & $4.6(0.0,9.2)$ & $33.5(24.7,40.4)$ & 28.9 \\
& 5. & 2 & $39.2(41.6,36.8)$ & $40.6(40.8,40.4)$ & 1.4 \\
\hline \multirow{2}{*}{ Virus } & 6 & 2 & $20.0(26.0,14.0)$ & $56.1(54.7,57.4)$ & 36.1 \\
Infection & 1 & 3 & $47.4(94.9,23.5,23.9)$ & $85.8(98.2,63.0,95.4)$ & 38.4 \\
\hline
\end{tabular}

- PBL $\left(5 \times 10^{6}\right)$ from normal individuals, patients with SS, or patients with acute viral infections were repeatedly obtained at intervals of more than a month, and cultured with or without HeLa-Ms cell monolayers for $18 \mathrm{~h}$. Both endogenous and augmented NK activities were assayed as described in Methods by ${ }^{51} \mathrm{Cr}$-release assay at 50:1 A/T ratio. The percentage of specific ${ }^{51} \mathrm{Cr}$-release in each independent experiment (in parenthesis) and the mean values are shown.

\$ Net increase $=$ augmented NK activity - endogenous NK activity.

virus persistently infected tumor cells was due primarily to IFN produced by the stimulation of these cells (16), and that the process was essentially responsible for the resistance of congenitally athymic nude mice to these virus persistently infected tumor cells in vivo (4). Thus, the depression of augmentability of $\mathrm{NK}$ activity in contact with HeLa-Ms cells in patients with SS could most likely be due $(a)$ to the reduced IFN production in response to HeLa-Ms cells, or (b) to the reduced responsiveness of NK (or their precursor) cells to IFN. To explore the first possibility, we examined the IFN production in vitro by the stimulation with HeLa-Ms cells in patients with SS and normal controls. The results are summarized in Fig. 2. It is clear that most of the patients with SS showed reduced IFN production in response to $\mathrm{HeLa}$-Ms cells in vitro (mean $55 \mathrm{U} / 0.1 \mathrm{ml}$ ) compared with normal controls (mean $545 \mathrm{U} / 0.1 \mathrm{ml}$ ), and the reduction was statistically significant $(P<0.01)$. The IFN thus produced was resistant to $\mathrm{pH} 2.0$ treatment, derived mainly from non-E-rosetting, nonadherent cells $(1,024$ $\mathrm{U}$ from $\mathrm{E}^{-}$fraction and $64 \mathrm{U}$ from $\mathrm{E}^{+}$fraction of $\mathrm{PBL}$ ), and was considered to be IFN $\alpha$.

Decreased responsiveness of NK activity to IFN in patients with SS. The second possibility was exam-

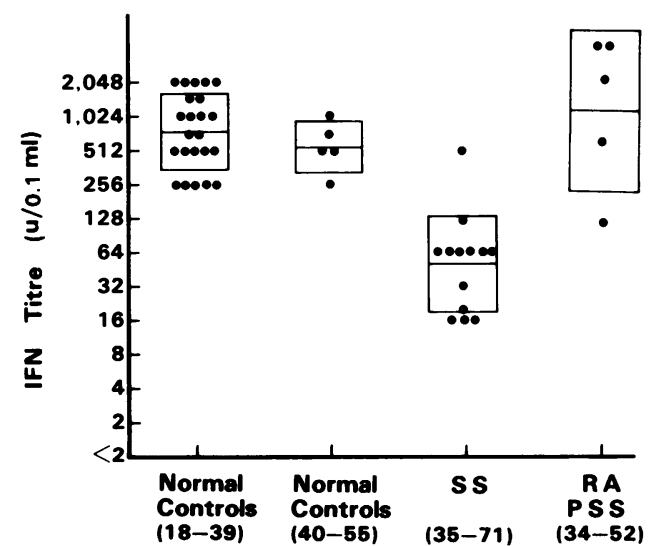

Figure 2 IFN production in vitro in response to HeLameasles cells by PBL from normal controls, patients with SS, and patients with RA or PSS. Freshly isolated PBL were cocultured with HeLa-measles monolayers for $24 \mathrm{~h}$. The culture supernates were harvested and assayed for antiviral (IFN) activity. The culture supernates of PBL alone either from normals or patients, or of $\mathrm{HeLa}-m e a s l e s$ cells alone did not have significant IFN activity $(<4 \mathrm{U} / 0.1 \mathrm{ml})$. Each point represents the mean value of one to four independant experiments of each individual. The mean $\pm S D$ of each group is also indicated. 
ined by pretreating the PBL with MLTC supernates of PBL and HeLa-Ms cells containing IFN activity as well as with purified IFN $\alpha$, and then by assaying NK activity. The representative cases of patient with SS and normal control are shown in Fig. 3. NK activity of PBL from normal donor was greatly augmented not only by the direct contact with HeLa-Ms cells (Fig. 3A) but also by the pretreatment with MLTC supernates (Fig. 3B). The capacity to augment NK activity of the MLTC supernate from normal PBL and HeLaMs was more potent than that of patient PBL and HeLa-Ms, conforming to the finding that the former contained more IFN activity $(512 \mathrm{U} / 0.1 \mathrm{ml})$ than the latter $(32 \mathrm{U} / 0.1 \mathrm{ml})$. Neither culture supernate of PBL alone nor that of HeLa-Ms alone (IFN $<2 \mathrm{U} / 0.1 \mathrm{ml}$ ) showed any significant effect on NK activity. The evidence that NK augmenting activity of MLTC supernates is really due to IFN is shown in Fig. 3C. The NK-augmenting activity of the supernate was completely abrogated by the coexistance of specific antihuman IFN $\alpha$-serum. Furthermore, the NK activity of normal PBL was similarly augmented by purified human IFN $\alpha$. In contrast, as shown in Fig. 3E and $F$, the NK activity of PBL from a patient with SS who showed no NK augmentation by HeLa-Ms cells (Fig. 3D) was not significantly affected by either MLTC supernates or purified IFN. Essentially similar results were obtained in three other cases of SS examined (Table II).

These results thus indicate that, in some of the patients with SS, not only the capacity to produce IFN in response to HeLa-Ms cells but also the responsiveness of NK activity to thusly produced IFN is severely impaired. Taken together, these findings strongly support the idea that basic dysfunction of NK system in these patients with SS resides in the potential responsiveness of the system to the exogenous stimuli such as virus persistently infected cells.

\section{DISCUSSION}

NK activity of PBL can be augmented by direct contact with virus persistently infected tumor cells (HeLaMs cells) in vitro. The augmentation of NK activity by HeLa-Ms cells has been shown to be primarily mediated by IFN produced by the cells with the same characteristics as NK effector cells, namely non-E-rosetting, nylon nonadherent cells, in response to HeLaMs cells. Thus, $(a)$ NK activity could be augmented by the culture supernates of PBL and HeLa-Ms cells that contained IFN activity, (b) NK augmenting activity of MLTC supernates was completely abrogated by the preincubation with specific antihuman IFN $\alpha$ antiserum, and $(c)$ NK activity was also augmented by

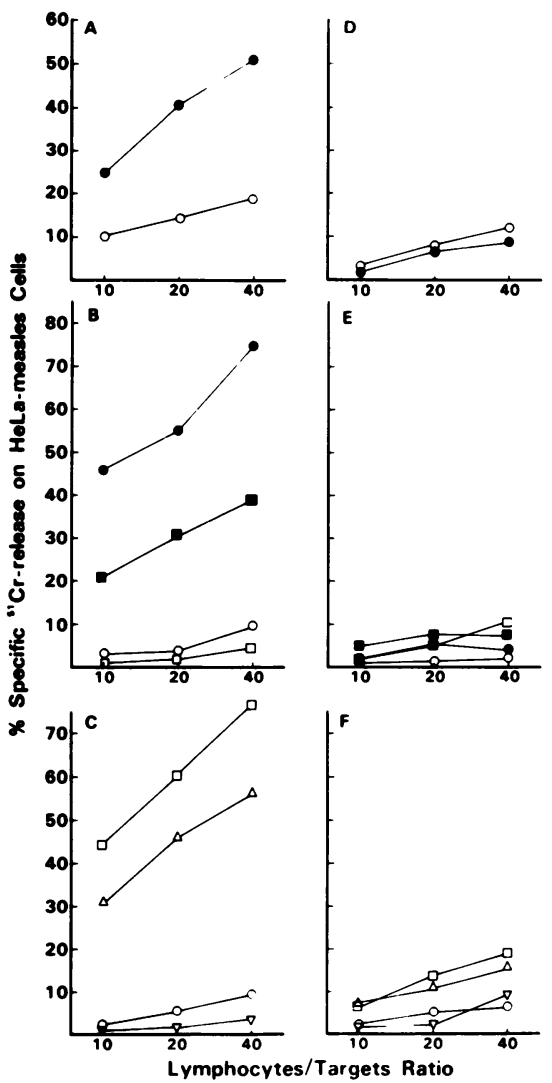

Figure 3 The representative experiment to show the lack of augmentation of NK activity in patients with SS by direct contact with HeLa-measles cells, by pretreatment with MLTC supernate containing IFN activity, or by pretreatment with chemically purified IFN. A, D: PBL from a normal control (A) or a patient with SS (D) were cultured alone (O) or with HeLa-measles cells (O) for $18 \mathrm{~h}$, recovered, and assayed for the cytotoxic activity against $\mathrm{HeLa}$-measles cells. B, E: PBL from a normal control (B) or a patient with SS (E) were cultured in the presence of $30 \%$ of MLTC supernates from normal PBL alone (IFN $<2 \mathrm{U} / 0.1 \mathrm{ml}$ ) (O), normal PBL and HeLa-measles cells (IFN 1,000 U/0.1 ml) (๑), Sjögren PBL alone (IFN $<2 \mathrm{U} / 0.1 \mathrm{ml}$ ) (ם), or Sjögren PBL and HeLa-measles cells (IFN $60 \mathrm{U} / 0.1 \mathrm{ml}$ ) (口). $18 \mathrm{~h}$ later, the cells were washed and cytotoxicity was assayed against HeLa-measles cells using 6-h ${ }^{51} \mathrm{Cr}$-release assay. Each point represents the mean value of triplicate culture. $\mathrm{C}, \mathrm{F}$ : PBL from a normal control $(C)$ or patient with SS $(F)$ were cultured in the presence of medium alone $(O), 5,000 \mathrm{U}$ of purified IFN $\alpha$ (ם), MLTC supernate containing 1,000 U of IFN activity $(\Delta)$, or the mixture of the MLTC supernate and antihuman IFN $\alpha$-antiserum ( $10^{-2}$ dilution), which had been preincubated for $2 \mathrm{~h}$ before the addition into the cultures $(\nabla)$. After 18-h culture, the cells were washed, and the cytotoxic activity was assayed against HeLa-measles cells. Each point represents the mean of triplicate determinations.

purified human IFN $\alpha$ (Fig. 3). Conforming to the results in murine experimental model system (16), it was thus shown that IFN played a crucial role in regulating NK activity in facing with virus persistently 
TABLE II

Failure to Augment NK Activity of PBL from Some of Patients with SS by the Pretreatment with MLTC Supernates Containing IFN Activity

\begin{tabular}{|c|c|c|c|c|c|c|c|}
\hline & & \multicolumn{6}{|c|}{ NK activity after treatment with MLTC supernates ${ }^{\circ}$} \\
\hline & & \multicolumn{2}{|c|}{ N-1 PBL } & \multicolumn{2}{|c|}{ SS-1 PBL } & \multicolumn{2}{|c|}{ SS-2 PBL } \\
\hline \multicolumn{2}{|c|}{$\begin{array}{c}\text { Donors of } \\
\text { PBL }\end{array}$} & $\begin{array}{l}\text { Alone } \\
<2 \text { Ut }\end{array}$ & $\begin{array}{c}\text { +HeLa-Ms } \\
512 \mathrm{U}\end{array}$ & $\begin{array}{l}\text { Alone } \\
<2 \mathrm{U}\end{array}$ & $\begin{array}{c}+ \text { HeLa-Ms } \\
\quad 32 \mathrm{U}\end{array}$ & $\begin{array}{l}\text { Alone } \\
<2 \mathrm{U}\end{array}$ & $\begin{array}{c}\text { +HeLa-Ms } \\
\quad 32 \mathrm{U}\end{array}$ \\
\hline & & $\%$ & $\%$ & $\%$ & $\%$ & & \\
\hline \multirow[t]{3}{*}{ Normal } & 1 & 12.6 & 63.6 & 14.0 & 31.9 & NE $\$$ & NE \\
\hline & 2 & 9.6 & 74.4 & NE & NE & 4.9 & 39.0 \\
\hline & 3 & 8.9 & 56.0 & NE & NE & NE & NE \\
\hline \multirow[t]{3}{*}{ Sjögren } & 1 & 1.2 & 1.8 & 0.9 & 1.9 & NE & NE \\
\hline & 2 & 5.2 & 16.3 & $\mathrm{NE}$ & NE & 7.6 & 9.3 \\
\hline & 3 & 2.1 & 3.9 & $\mathrm{NE}$ & $\mathrm{NE}$ & 10.7 & 8.2 \\
\hline
\end{tabular}

- PBL $\left(5 \times 10^{6}\right)$ from normal controls or patients with SS were cultured with or without HeLa-Ms cell monolayers for $24 \mathrm{~h}$, and the culture supernates (MLTC supernates) were harvested. Freshly isolated PBL $\left(2 \times 10^{6}\right)$ from the same or different individuals (as indicated by numbers) were incubated in the medium containing $30 \%$ of various combinations of MLTC supernates for $18 \mathrm{~h}$, washed, and assayed for NK activity against HeLa-Ms cells by regular ${ }^{51} \mathrm{Cr}$-assay at $40: 1 \mathrm{~A} / \mathrm{T}$ ratio.

$\downarrow$ IFN titer in each MLTC supernate.

$\S$ Not examined.

infected cells. The present results indicate that patients with SS have generally reduced augmentability of NK activity in response to HeLa-Ms cells (Fig. 1). Using the most popular NK target cells, K562, essentially similar results were obtained, although the reduction tended to be more striking when HeLa-Ms cells were used as target cells (data not shown). The degrees of reduction, however, widely varied from one patient to another. Thus, approximately half of the patients with SS had severely impaired augmentation of NK activity, whereas the other half had the augmentation close to normal controls. On the other hand, almost all patients with SS have been shown to have reduced capacity to produce IFN in response to HeLa-Ms cells in vitro. The degree of the reduction in NK augmentability did not necessarily correlate with that of IFN production in each patient with SS. Thus, it seemed necessary to examine the responsiveness of NK activity to IFN, especially in those who showed severely reduced NK augmentation by the contact with HeLa-Ms cells. The results clearly indicate that these patients show no significant augmentation of NK activity by the addition of exogenous, IFN-containing MLTC supernates as well as of purified IFN. The patients who had relatively normal NK augmentation showed close to normal response to those exogenous IFN. Thus one has to consider both the capacity to produce IFN and the responsiveness of NK cells to thusly produced IFN in order to evaluate overall potential responsiveness of $\mathrm{NK}$ effector system to the stimulation such as virus-infected cells. Clinically, the severity of the impairment in NK responsiveness seemed to be correlated with the presence of systemic manifestations of SS. The "low responders" listed in Table II had various extraglandular manifestations, including hypergammagloblinemic purpura (case 1), generalized lymphoid hyperplasia (cases $1,2,4)$, and pleuropulmonary involvement (case 2), as well as concomitant viral infections (cases 1,3). The close-to-normal responders, on the other hand, had only glandular disease with or without RA. Conforming to the previous reports $(21,22)$, the patients with SLE who had not been treated before showed severe depression of NK augmentability, whereas those with RA had normal NK activity. In contrast to these chronic inflammatory diseases, the patients who had acute hepatitis and lymphoadenopathy most likely due to viral infections clearly showed transiently elevated endogenous NK activity with further augmentation by HeLa-Ms cell stimulation.

At present, the basis for the impaired functions of NK-IFN system in patients with SS as well as SLE is not clear. None of these patients had been receiving corticosteroids, which is shown to depress NK activity (25). Some of these with SS were receiving nonsteroidal antiinflammatory drugs including aspirin. It seems, 
however, very unlikely that these medications had affected the functions of NK-IFN system in patients with SS, because $(a)$ the patients with RA who were also taking these drugs showed normal NK activity, and $(b)$ most of the low responders in patients with SS were not receiving any of these drugs. Recently, it was reported that the reduced NK activity in patients with SLE was due to antilymphocyte antibodies in patients' sera (22). We also observed the inhibitory effect of sera from some of the patients with SLE on the NK activity of normal individuals. On the other hand, our preliminary experiments failed to show any such effect of the sera from SS patients, whose NK activity was severely depressed, on the NK activity of normal controls. Furthermore, the depressed NK activity of a patient with SS has never been restored after repeated plasmapheresis (Table I). We feel it unlikely that impaired NK-IFN function in SS patients is secondary to serum factors in these patients and may involve different underlying mechanisms from that in some of the SLE patients. The possible mechanisms might include, $(a)$ the paucity of NK (or precursor) cells, which might be also responsible for IFN production, in the recirculation pool due to exhaustion by chronic persistent stimulation or to sequestration by local stimulations, (b) some metabolic abnormalities in NK as well as IFN-producing cells, $(c)$ involvement of some kind of suppressor cells, although we failed to show the evidence for this by mixed experiments (data not shown), and $(d)$ genetic influence, in which genes shown to be linked to SS might also affect the functions of NK-IFN system. The question remains to be investigated.

Recently, Virelizier et al. (26) reported a girl who had a chronic disease characterized by fever, lymphoid hyperplasia, interstitial pneumonitis, thrombocytopenia, and hypergammagloblinemia after EB virus infection. The patient has been shown to have a defect in IFN production in response to EBV-transformed cells in vitro as well as reduced NK activity (27). In patients with multiple sclerosis in which persistent viral infection is suspected to be involved in pathogenesis (28), the dysfunction of NK-IFN system was also reported (29). Recently, we observed that the children with subacute sclerosing panencephalitis had severely depressed NK functions, especially against HeLa-Ms cells (manuscript in preparation). Although the involvement of (persistent) viral infections in SS is not established, it seems thus possible that impaired function of NK-IFN system could be one of the predisposing factors for the development of the disease, in particular for the systemic manifestations. In patients with SS, rather frequent development of lymphoproliferation including malignant lymphomas, has long been recognized (30) and extensively discussed by Talal et al. (31). In this context, it is noted that Sullivan et al. (32) recently reported that most of the patients with X-linked lymphoproliferative syndrome (XLP) showed severely depressed NK activity. In these patients, extremely high incidence of lymphoma have been recognized (33). Lymphoid hyperplasia including malignant lymphomas has been also frequently reported in patients with Chédiak-Higashi syndrome (34), which is the first genetic disease shown to have severe impairment in NK activity (35). These results may suggest possible relationship between dysfunction of NK-IFN system and lymphoproliferation in these diseases including SS as common immunological basis, although the specific genetic/etiological factors should be quite different from each other.

\section{ACKNOWLEDGMENT}

This paper as supported by a grant from the Ministry of Health, Japan.

\section{REFERENCES}

1. Bancroft, G. J., G. R. Shellam, and J. E. Chalmer. 1981. Genetic influences on the augmentation of natural killer (NK) cells during cytomegalovirus infection: correlation with patterns of resistance. J. Immunol. 126: 988-994.

2. Haller, O., M. Hasson, B. Kiessling, and H. Wigzell. 1977. Role of nonconventional natural killer cells in resistance against syngeneic tumor cells in vivo. Nature (Lond.). 270: 609-611.

3. Talmage, J. E., K. M. Meyers, D. J. Prier, and J. R. Starkey. 1980. Role of NK cells in tumor growth and metastasis in beige mice. Nature (Lond.). 284: 622-624.

4. Reid, L. M., N. Minato, I. Gresser, J. Holland, A. Kadish, and B. R. Bloom. 1981. Influence of anti-mouse interferon serum on the growth and metastasis of tumor cells persistently infected with virus and of human prostatic tumors in athymic nude mice. Proc. Natl. Acad. Sci. U. S. A. 78: 1171-1175.

5. Gidlund, M., A. Orn, H. Wigzell, A. Senik, and I. Gresser. 1978. Enhanced NK activity in mice injected with interferon and interferon inducers. Nature (Lond.). 273: 759-760.

6. Trinchieri, G., and D. Santoli. 1978. Anti-viral activity induced by culturing lymphocytes with tumor-derived or virus-transformed cells. Enhancement of human natural killer cell activity by interferon and antagonistic inhibition of susceptibility of target cells to lysis. J. Exp. Med. 147: 1314-1333.

7. Block, K. J., W. W. Beuhanan, M. J. Wohl, and J. J. Bunim. 1965. Sjögren syndrome. A clinical, pathological, and serological study of sixty-two cases. Medicine. 44: 187-231.

8. Shearn, M. A., W. H. Tu, B. G. Stephens, and J. C. Lee. 1970. Virus-like structures in Sjögren syndrome. Lancet. I: $568-569$.

9. Györkey, F., J. G. Sinkovicz, K. W. Min, and P. Györkey. 1972. A morphologic study on the occurrence and distribution of structures resembling viral nucleocapsid in collagen diseases. Am. J. Med. 53: 148-158.

10. Anderson, L. G., and N. Talal. 1972. The spectrum of benign to malignant lymphoproliferation in Sjögren syndrome. Clin. Exp. Immunol. 10: 199-221. 
11. Leventhal, B. G., D. S. Waldorf, and N. Talal. 1967. Impaired lymphocyte transformation and delayed hypersensitivity in Sjögren syndrome. J. Clin. Invest. 46: 1338-1345.

12. Miyasaka, N., B. Sauvezie, D. A. Piece, T. E. Daniels, and N. Talal. 1980. Decreases autologous mixed lymphocyte reaction in Sjögren syndrome. J. Clin. Invest. 66: $928-933$.

13. Herberman, R. B., M. E. Nunn, and D. H. Laurin. 1975. Natural cytotoxic reactivity of mouse lymphoid cells against syngeneic and allogeneic tumors. I. Distribution of reactivity and specificity. Int. J. Cancer 16: 216-229.

14. Kiessling, R. E., E. Klein, and H. Wigzell. 1975. "Natural" killer cells in the mouse. I. Cytotoxic cells with specificity for mouse Moloney leukemia cells. Eur. J. Immunol. 5: 112-119.

15. Minato, N., B. R. Bloom, C. Jones, J. Holland, and L. Reid. 1979. Mechanism of rejection of virus persistently infected tumor cells by athymic nude mice. J. Exp. Med. 149: $1117-1133$.

16. Minato, N., L. Reid, H. Cantor, P. Leygyel, and B. R. Bloom. 1980. Mode of regulation of natural killer cell activity by interferon. J. Exp. Med. 152: 124-137.

17. Trinchieri, G., D. Santoli, R. R. Dee, and B. B. Knowles. 1978. Anti-viral activity induced by culturing lymphocyte with tumor-derived or virus-transformed cells. Indentification of the antiviral activity as interferon and characterization of the human effector lymphocyte subpopulation. J. Exp. Med. 147: 1299-1313.

18. Stutman, O. 1978. Spontaneous, viral and chemically induced tumors in the athymic nude mice. In The Nude Mouse in Experimental and Clinical Research. J. Fogh and B. Giovanella, editors, Academic Press, Inc., New York. 411-465.

19. Herberman, R. B. 1978. Natural cell-mediated cytotoxicity in nude mice. In The Nude Mouse in Experimental and Clinical Research. J. Fogh and B. Giovanella, editors, Academic Press, Inc., New York, 135-138.

20. Holland, J. J., B. L. Semler, C. Jones, J. Perrault, L. Reid, and L. Roux. 1978. Role of DI, virus mutation, and host response in persistent infections by enveloped RNA viruses. ICN-UCLA Symp. Mol. Cell Biol. 11: 57-75.

21. Oshimi, K., M. Sumiya, N. Gonda, S. Kano, and F. Takaku. 1979. Natural killer cell activity in systemic lupus erythematosus. Lancet. II: 1023-1024.

22. Goto, M., K. Tanimoto, and Y. Horiuchi. 1980. Natural cell mediated cytotoxicity in systemic lupus erythematosus suppression by antilymphocyte antibody. Arthritis Rheum. 23: 1274-1281.

23. Welsh, R. M., and R. M. Zinkernagel. 1977. Heterospecific cytotoxic cell activity induced during first three days of acute lymphocytic choriomeningitis virus infection in mice. Nature (Lond.). 268: 646-647.

24. Quinnan, G. V., and J. E. Manischenitz. 1979. The role of natural killer cells and antibody-dependent cell-mediated cytotoxicity during murine cytomegalo-virus infection. J. Exp. Med. 150: 1549-1554.

25. Oshimi, K., N. Gonda, M. Sumiya, and S. Kano. 1980. Effect of corticosteroid on natural killer cell activity in systemic lupus erythematosis. Clin. Exp. Immunol. 40: 83-88.

26. Virelizier, J. L., G. Lenoar, and C. Griscelli. 1978. Persistent Epstein-Barr virus infection in a child with hypergammaglobulinemia and immunoblastic proliferation associated with a selective defect in immune interferon secretion. Lancet I: 231-234.

27. Lipinski, M., J. L., Virelizier, T. Tursz, and C. Griscelli, 1980. Natural killer and killer cell activities in patients with primary immunodeficiencies and defects in immune interferon production. Eur. J. Immunol. 10: 246249.

28. Maugh, T. H. 1977. Multiple sclerosis: two or more viruses may be involved. Science (Wash., D. C. ). 195; 768-769.

29. Neighbour, P. A., A. E. Miller, and B. R. Bloom. 1981. Interferon responses of leukocytes in multiple sclerosis. Neurology. In press.

30. Kassan, S. S., T. L. Thomas, H. M. Moutsopoulas, R Houer, R. P. Kimberly, D. R. Budman, J. Costa, J. L. Decker, and T. M. Chused. 1978. Increased risk of lymphoma in sicca syndrome. Ann. Intern. Med. 89: 888892.

31. Talal, N. 1977. Autoimmunity and lymphoid malignancy: manifestations of immunoregulation disequilibrium. In Autoimmunity. N. Talal, editor, Academic Press, Inc., New York, 183-206.

32. Sullivan, J. L., K. S. Byron, F. E. Brewster, and D. T. Purtilo. 1980. Deficient natural killer cell activity in Xlinked lymphoproliferative syndrome. Science (Wash., D. C.). 210: 543-545.

33. Purtilo, D. T., L. Paquin, P. DeFlorio, F. Virzi, and R. Sakhuja. 1979. Immunodiagnosis and immunopathogenesis of X-linked recessive lymphoproliferative syndrome. Semin. Hematol. 16: 309-343.

34. Page, A. R., H. Beriendes, J. Warner, and R. A. Good. 1962. The Chediak-Higashi syndrome. Blood. 20: 330343.

35. Haliotis, T., J. Roder, M. Klein, J. Ortaldo, A. Fauci, and R. B. Herberman. 1980. Chediak-Higashi gene in humans. I. Impairement of natural killer function. J. Exp. Med. 151: 1039-1048. 